\title{
Maternal and perinatal outcome in trial of labour after caesarean at tertiary care hospital: a prospective observational study
}

\author{
Ingle Sharad Prabhakarrao, Shalaka Bansode*, Sumathi Balakuduru
}

Department of Obstetrics and Gynecology, RDT Hospital, Bathalapalli, Ananthapur District, Andhra Pradesh, India

Received: 10 November 2020

Revised: 12 December 2020

Accepted: 14 December 2020

\author{
*Correspondence: \\ Dr. Shalaka Bansode, \\ E-mail: shalakabansode@gmail.com
}

Copyright: (C) the author(s), publisher and licensee Medip Academy. This is an open-access article distributed under the terms of the Creative Commons Attribution Non-Commercial License, which permits unrestricted non-commercial use, distribution, and reproduction in any medium, provided the original work is properly cited.

\begin{abstract}
Background: To compare maternal and perinatal outcomes in trial of labor after cesarean (TOLAC) and Emergency repeat cesarean delivery (ERCD).

Methods: Prospective observational study at tertiary care center for one year. Selection of candidates for Vaginal Birth after caesarean section (VBAC) was based on the 2010 American College of Obstetricians and Gynecologists' (ACOG) recommendation. The maternal outcome was observed in the form of VBAC success rate, maternal complications, number of days in a hospital stay, The perinatal outcome was observed as 5 minute Apgar score and need for neonatal intensive care unit (NICU) admission.

Results: 250 patients were given trial for vaginal delivery. VBAC success rate was 169/249 (67.9\%). 80/249(32.1\%) patients required repeat CS. Cases with Bishop score $>6$ had more rate of vaginal delivery (89.6\%) as compared to Bishop score $\leq 6(17.4 \%)(\mathrm{p}=<0.01)$. Spontaneous labour had better VBAC success rate $(91.8 \%)$ than induced labour $(55.5 \%)(\mathrm{p}=<0.01) .8 / 12(66.6 \%)$ subjects with history of previous vaginal deliveries delivered vaginally. 5/169 of VBAC babies had low 5-minute Apgar score as compared to 3/80 from repeat CS.

Conclusions: VBAC has the benefits of short hospital stay, decreased morbidity and less expenditure. Considering the fact that fetal morbidity and mortality due to TOL is comparable with the women labouring without a scar, TOL may be encouraged. Women can be given TOL with careful monitoring and taken for emergency LSCS on minimal indication and can be the best answer to management of previous one CS in labour.
\end{abstract}

Keywords: Emergency repeat cesarean delivery (ERCD), Trial of labour after caesarean (TOLAC), Vaginal birth

\section{INTRODUCTION}

Caesarean section is a common operation performed on women, with reported rates varying across the world. In modern obstetrics the incidence of caesarean section has been increased. According to the World Health Organization (WHO) in 2015, CS rates in women who had a previous CS ranged between 78.1 and $79.4 \%$ in high-income countries, 85.2 and $87.5 \%$ in middle-income countries and 63.2 and $72.1 \%$ in low-income countries. ${ }^{1,2}$ Caesarean delivery now a days become safe due to improvement in surgical techniques, availability of blood transfusion and antibiotics, operative skills, effective anaesthesia. Even though caesarean birth has become safer it is not without morbidity. In obstetrics practice, one of the major topics of debate is decision making in caesarean birth. Before 1970, deliveries by CS were considered as indication for CS in subsequent pregnancies, reflecting a concern that uterine scar tissue might rupture during labour. In the 1980 s, the dictum 'once a caesarean always caesarean', espoused by Craigin. ${ }^{3}$ In 1916, was revised and a trial of labour (TOL) in women with history of CS was proposed in an attempt to reduce repeat $\mathrm{CS}$. With rising rates of caesarean deliveries all over the world, the largest indication of caesarean section is, repeat caesarean section because of 
previous caesarean delivery. Reducing the rate of primary caesarean section would be the most logical approach to reduce the rate of caesarean delivery. various studies have shown that vaginal birth after caesarean section is now relatively safe and is now commonly practiced. Vaginal delivery after caesarean section provides best obstetric carrier to a patient. With advent of lower segment caesarean section, the incidence of scar rupture as compared to classical scar has reduced considerably. But we cannot predict capacity of uterine scar to withstand stress and strain in subsequent pregnancies and labour.

Health of fetus has a significant role in making decision for caesarean birth. The rate of repeat caesarean is due to increased awareness and use of antenatal and intranatal fetal monitoring. The perinatal morbidity and mortality can be decreased to minimum by selecting proper cases for TOLAC and by choosing correct time for elective caesarean section. The present study is an attempt to analyze the existing trends at our hospital in management of patients with previous LSCS in subsequent pregnancies.

\section{METHODS}

This prospective observational study has been done in department of Obstetrics and Gynecology at Rural Development Trust Hospital, Bathalapalli for a period of one year from October 2014 to September 2015.250 women were included in this study. The participants who fulfilled the inclusion and exclusion criteria of the study were counseled and motivated for TOLAC. Informed consent of the participant was obtained at the time of admission for delivery. TOL refers to trial for vaginal delivery, which may end as successful vaginal birth after caesarean (VBAC) or failed TOL resulting in repeat section.

Participants belonged to booked and unbooked category. Booked patients at their first antenatal visit were registered and has been called regularly for checkups monthly up to 28 weeks and then every 15 days up to 36 weeks and weekly till term. Detailed history was taken regarding indication for previous caesarean section (recurrent/non-recurrent),type of previous caesarean section, time of lower segment caesarean section in relation to labour, number of previous caesarean sections, vaginal deliveries prior to subsequent to caesarean section, evidence of any medical condition precluding vaginal delivery, any post-operative complication during convalescence in previous section , any other surgery performed previously, birth weight of neonate.

\section{Inclusion criteria}

Women willing for TOLAC, Women with one previous lower segment caesarean section (LSCS), Women with previous LSCS done more than 18 months before, Women with gestational age $\geq 37$ weeks who will come in spontaneous labour with live pregnancy with haemoglobin $\geq 8 \mathrm{~g} / \mathrm{dl}$, Women with gestational age at 40 weeks and 3 days with live pregnancy with haemoglobin $\geq 8 \mathrm{~g} / \mathrm{dl}$ willing for TOLAC.

\section{Exclusion criteria}

Women not willing for TOLAC, Women with more than one previous LSCS, Women with history of previous classical caesarean section or hysterotomy or myomectomy, Women With haemoglobin $<8 \mathrm{~g} / \mathrm{dl}$, intrauterine fetal death (IUD), Previous LSCS done for contracted pelvis, Big baby with weight more than $4 \mathrm{~kg}$. Women with HIV, HbsAg positive status, Women with Thrombocytopenia, ITP, Bleeding disorders/O postoperative period infection, Malpresentation, abnormal placentation., Uterine anomalies.

Selection of candidates for TOLAC by the obstetrician was based on the 2010 American College of Obstetricians and Gynecologists' (ACOG) recommendation which specified that such a candidate should have no more than one prior lower segment Caesarean delivery, clinically adequate pelvis, no other uterine scars or previous rupture, and the availability of obstetricians and anesthetists and other requisite personnel to monitor the active labour and carry out a timely Caesarean delivery. 1 For the patients selected for the study, a decision was made at 37 weeks of gestation regarding the trial of scar after ascertaining the pelvic adequacy and suitability of other factors. Spontaneous labour (in the absence of any complication indicating early induction of labour) was awaited until the end of the 40weekand 3 days. After this time, induction of labour was performed with Foleys followed by inj. Oxytocin or only with inj. Oxytocin depending on Bishops score in individualized case. Women coming in spontaneous labour at or after 37 weeks of gestation were assessed for uterine activity, Scar tenderness, and fetal heart rate, clinically estimated fetal weight, Bishop Score and were admitted in labour room for TOLAC. Fetal heart rate monitoring was done with cardiotocography (CTG). Women were watched for spontaneous progress of labour if progressing well, if not labour was augmented with injection Oxytocin 2.5 International units (IU and titrated depending on progress of labour, during labor, women were monitored using a partogram including regular auscultation of the fetal heart at least once every $30 \mathrm{~min}$ and regular prompting for vaginal bleeding, uterine tenderness and staining of liquor. The maternal outcome were observed in the form of VBAC success rate, maternal complications, number of days in a hospital stay, The perinatal outcome was observed in the form of 5 minute Apgar score and need for neonatal intensive care unit (NICU) admission.

The collected data was analyzed with SPSS 16.0 version. The data descriptive statistics frequency analysis, percentage analysis were used for categorical variables and for continuous variables the mean and standard deviation were used. Chi-Square test was used. 


\section{RESULTS}

This study was conducted at Rural Development Trust Hospital Bathalapalli with 250 pregnant women who have had one previous lower segment caesarean section (LSCS) done. Results were evaluated as Total number of successful vaginal deliveries after TOLAC, Total number of women with failed TOLAC and went for emergency LSCS. Maternal outcome was assessed by maternal complications, number of days in hospital stay. Perinatal outcome was assessed by Apgar score and NICU admission.
In present study, 250 patients were given trial for vaginal delivery that had one previous LSCS. One patient withdrawn from the study and opted for emergency repeat caesarean Section (ERCD) after being admitted for TOLAC. $169 / 249(67.9 \%)$ of patients could be delivered vaginally either normal vaginal delivery or instrumental delivery and $80 / 249$ (32.1\%) patients required repeat caesarean section. VBAC rate in present study is $67.9 \%$.

Demographic and obstetric data of study group is mentioned in the Table 1.

Table 1: Demographic and obstetric data of study group.

\begin{tabular}{|c|c|c|c|c|}
\hline & & Vbac $(n=169)$ & Repeat caesarean section $(n=80)$ & $P$ value \\
\hline Maternal age & & $24.8 \pm 3.4$ & $24.6 \pm 3.3$ & 0.5 \\
\hline Gestational age at delivery & & $39.13 \pm 1.0$ & $39.15 \pm 1.0$ & 0.84 \\
\hline $\begin{array}{l}\text { Mean interconceptional period } \\
\text { (months) }\end{array}$ & & $29.9 \pm 6.4$ & $21.35 \pm 3.3$ & $<0.001$ \\
\hline Bishop's score >6 & & $156 / 169(92.3 \%)$ & $18 / 80(22.5 \%)$ & $<0.001$ \\
\hline \multirow{2}{*}{ Type of labour } & $\begin{array}{l}\text { Spontaneous } \\
(\mathrm{n}=85)\end{array}$ & $78(91.7 \%)$ & $7(8.2 \%)$ & \multirow{2}{*}{$<0.001$} \\
\hline & $\begin{array}{l}\text { Induced } \\
(\mathrm{n}=164)\end{array}$ & $91(55 \%)$ & $73(44.5 \%)$ & \\
\hline 5- minute apgar $<7$ & & $5 / 169(3 \%)$ & $3 / 80(3.7 \%)$ & 0.71 \\
\hline
\end{tabular}

VBAC - Vaginal Birth After Caesarean, NICU-Neonatal Intensive Care Unit

Table 2: Indications of repeat caesarean section during present pregnancy.

\begin{tabular}{|lll|}
\hline $\begin{array}{l}\text { Indication for } \\
\text { LSCS }\end{array}$ & No. of cases & Percentage $(\%)$ \\
\hline $\begin{array}{l}\text { Non progress of } \\
\text { labour }\end{array}$ & 28 & 35.0 \\
\hline Fetal distress & 22 & 27.5 \\
\hline $\begin{array}{l}\text { Fetal distress } \\
\text { with meconeum } \\
\text { stained liquor }\end{array}$ & 8 & 10.0 \\
\hline $\begin{array}{l}\text { Meconeum } \\
\text { stained liquor }\end{array}$ & 5 & 6.25 \\
\hline $\begin{array}{l}\text { Severe fetal } \\
\text { bradycardia }\end{array}$ & 12 & 15.0 \\
\hline $\begin{array}{l}\text { Maternal } \\
\text { tachycardia }\end{array}$ & 5 & 6.25 \\
\hline Total & 80 & 100 \\
\hline
\end{tabular}

There was no difference in mean maternal age and mean gestational age at delivery. There was significant difference in the mean inter-conceptional period (months) of VBAC $(29.9 \pm 6.4)$ and repeat CS group $(21.35 \pm 3.3) \mathrm{p}$ value $<0.001$. The present study, women with history of previous vaginal deliveries and one $\mathrm{CS}$ have more chances of success for TOL, as out of 12 such cases 8 $(66.6 \%)$ delivered vaginally and $4(33.3 \%)$ taken in for emergency CS. 174/249 patients presented with Bishop score $>6$ at the time of admission. Out of these $156(89.6 \%)$ had vaginal delivery, as compared to those with Bishop score $\leq 6$ of which only $13 / 75(17.4 \%)$ patients delivered vaginally $(\mathrm{p}=<0.001)$. Most common chief complaint with which patients presented was pain in abdomen $(59.83 \%)$ followed by preterm rupture of membranes (PROM) with pain in abdomen $(7.6 \%)$ and PROM (12.9\%). 85(34.13\%) patients reported spontaneous labour. Among these patients, 78(91.8\%) delivered vaginally and $7(8.2 \%)$ patients had repeat caesarean sections.

Table 3: Maternal complications in VBAC cases.

\begin{tabular}{|lll|}
\hline $\begin{array}{l}\text { Maternal } \\
\text { complications }\end{array}$ & No. of cases & Percentage $(\%)$ \\
\hline $\begin{array}{l}\text { Postpartum } \\
\text { haemorrhage }\end{array}$ & 5 & 2.0 \\
\hline Blood transfusion & 3 & 1.2 \\
\hline Cervical tear & 5 & 2. \\
\hline Paraurethral tear & 2 & 0.8 \\
\hline $\begin{array}{l}\text { Lateral vaginal } \\
\text { wall tear }\end{array}$ & 3 & 1.2 \\
\hline Nil & 231 & 92.8 \\
\hline Total & 249 & 100 \\
\hline
\end{tabular}

A total $164(65.87 \%)$ women required induction of labour. Among these 42 patients were induced by Foleys followed by acceleration (if required) with oxytocin infusion. 91 patients were induced by artificial rupture of membranes followed by acceleration (if required) with oxytocin infusion and 31 patients were induced with 
oxytocin infusion. Of the induced cases $91(55.5 \%)$ delivered vaginally and $73(44.5 \%)$ delivered by CS. Thus, VBAC success rate for spontaneous labour was 91.8\% whereas it was $55.5 \%$ in patients who induced for TOLAC $p$ value of spontaneous onset of labour is significant $(\mathrm{p}=<0.01)$.

\section{Table 4: Intraoperative findings in emergency repeat $\mathrm{CS}$.}

\begin{tabular}{|lll|}
$\begin{array}{l}\text { Intraoperative } \\
\text { findings }\end{array}$ & No. of cases & Percentage $(\%)$ \\
\hline Adhesions & 16 & 20. \\
\hline Bladder advanced & 11 & 13.7 \\
\hline Scar dehiscence & 7 & 8.75 \\
\hline Ruptured uterus & 3 & 3.75 \\
\hline Nil & 43 & 53.7 \\
\hline Total & 80 & 100 \\
\hline
\end{tabular}

As per shown in the Table 2, Non progress of labour was the main indication of repeat caesarean section in present pregnancy in $35 \%$ of cases. Other indications were mainly meconium-stained liquor, scar tenderness, fetal distress, maternal tachycardia, and severe fetal bradycardia.

Table 3 shows maternal complications. In patients who delivered vaginally after previous caesarean section., most of complications were mostly in the form of trauma to lower genital tract 10/249 (4\%). Intraoperative findings in emergency repeat CS are shown in Table 4 - during repeat $\mathrm{CS}$, difficulty in opening abdomen due to adhesions between omentum and peritoneum and bladder were seen in $20 \%$ cases. Scar dehiscence was seen in $7 / 249$ cases $(2.81 \%)$. Obstetrics hysterectomy was done in one patient. Bladder advancement/edema was seen in $(13.7 \%)$ cases. Uterine rupture was seen in $1.2 \%$ (3/249). Post-partum hemorrhage was seen in 5(2\%) cases. Out of these $3 / 80(3.7 \%)$ cases were from repeat CS group and $2 / 169(1 \%)$ cases were from VBAC group. 3 cases in which blood transfusion was required were from emergency LSCS group following TOL.

The average duration of hospital stay for women having a successful VBAC was lower (1.8days) than women who required a repeat $\mathrm{CS}$ ( $\geq 3$ days). In the present study 96.8\% babies had normal Apgar score .8 (3.2\%) babies had Apgar score $<7$. Out of these 3 were from VBAC group and 5 were from repeat CS group. There were total 14 NICU admissions, which constituted $5.6 \%(14 / 249)$ of all births. Out of these 8 cases were from VBAC group and 6 were from repeat CS group.

The most common indications for NICU transfer were respiratory distress syndrome, and not cried immediately after birth. There was one neonatal death in the present study which was from repeat CS group. This case had ruptured uterus intraoperatively.

\section{DISCUSSION}

The American College of Obstetricians and Gynecologists (ACOG) updated their guidelines concerning vaginal delivery after previous caesarean section. The ACOG Committee on Obstetrics: Maternal and Fetal Medicine stated; "the concept of routine repeat caesarean birth should be replaced by a specific indication for a subsequent abdominal delivery and in the absence of a contraindication, a woman with one previous caesarean delivery with a low transverse incision should be counseled and encouraged to attempt labour in her current pregnancy". ${ }^{4}$ In the present practice since the indication for caesarean have been widened, the trial of labour for properly selected patients is the ideal and safest mode of management. In present study 250 patients were given trial for vaginal delivery who had one previous LSCS .out of that 1 patient opted for elective LSCS after admitted for TOLAC, so 249 women were included in the study.

VBAC success rate in present study was $67.9 \%$ almost comparable to the study conducted by Agrawalet al., $(83 \%) .^{5}$ As per study conducted by Landon et al., the success rate of VBAC was significantly higher (93 $\% \mathrm{Vs} 7 \%$ ) in cases with cervical dilatation of more than 3 $\mathrm{cm}$ as against less than $3 \mathrm{~cm}$ at the time of admission. ${ }^{6}$ Grobman WA et al suggested that an unfavourable cervix decreases the chance of success to the greatest extent. ${ }^{7}$ Similarly in present study, women presented with good Bishop Score ( $>6)$ at the time of admission had good rate of vaginal delivery; almost $89.6 \%$ as compared to those with poor Bishop score $(\leq 6)$ of which only $17.4 \%$ patients delivered vaginally $(\mathrm{p}=<0.01)$.

As per Sims EJ et al, Induced labour is less likely to result in VBAC than spontaneous labour. ${ }^{8}$ In present study, $85(34.13 \%)$ patients reported spontaneous labour. Among these patients, $78(91.8 \%)$ delivered vaginally and $7(8.2 \%)$ patients had repeat caesarean sections. VBAC success rate was $55.5 \%$ in patients who were induced for TOLAC.

Shipp et al, reported that the rate of scar rupture was $2.3 \%$, when the interval was less than 18 months as compared to $1 \%$, when the interval was more than 18 months. ${ }^{9}$ Phelan et al reported scar dehiscence in $1.9 \%$ cases and uterine rupture in $0.3 \%$ cases. ${ }^{10}$ Dayal et al reported higher rates $(4.2 \%)$ of scar rupture. ${ }^{11}$ Lower segment caesarean scar has a minimum risk $(0.2-1.5 \%)$ of rupture during vaginal delivery. Morbidity was three times more in cases, which required a repeat CS than those with a successful VBAC delivery. ${ }^{12}$ There was no maternal mortality in the present study. In the present study the rate of scar rupture was $1.2 \%$ and in 2 cases the interconceptional period was less than 2 years. As per Nigam A.et al the most common indications for a repeat emergency LSCS were fetal distress and non-progress of labour, together constituting about $80 \%$ of the total number of repeat emergency LSCS. ${ }^{13}$ In the present study 
also most common indications for a repeat emergency LSCS were fetal distress and non-progress of labour $(72.5 \%)$.

Mozurkewich and Hutton et al put another potential argument in support of VBAC that a trial of labour is associated with reduced risks for the mother compared with those of a repeat caesarean delivery. ${ }^{14}$ Maternal mortality does not differ significantly between women undergoing TOL compared with that of an ERCD. In present study most of complications were mostly in form of trauma to lower genital tract trauma- 4\% (10/249) in cases who delivered vaginally with previous caesarean section. Also, in $20 \%$ cases (16/80) there was difficulty in opening abdomen due to intraabdominal adhesions.

Traynor JD did a survey of the benefits of a successful VBAC and found out that a shorter hospital stay in a VBAC delivery has a positive impact on the psychology of the woman and decreases the total cost of hospitalization. ${ }^{15}$ In a study by Horowitz BJ et al, Trial of labour was also associated with a decreased length of stay when compared with elective caesarean section $(2.48+$ 0.88 days vs. $3.62+/-0.57$ days, $(\mathrm{p}<0.001) .{ }^{16}$ In the present study $-98.2 \%$ of vaginal deliveries had hospital stay of 1 day; while hospitals stay in $98.8 \%$ LSCS was $\geq$ 3 days.

A study was conducted by Hibbard et al that showed blood loss was lower in women who attempted vaginal births after caesarean. ${ }^{17}$ Patients who experience failed vaginal birth after caesarean have higher risks of uterine disruption and infectious morbidity compared with patients who have successful vaginal births after caesarean or elective repeat caesarean delivery. In present study maternal morbidity in the form of post-partum hemorrhage (PPH) was in 5/249 (2\%) cases of which 3 cases were from repeat CS group and 2 cases from VBAC group. More chances of PPH in cases from repeat $\mathrm{CS}$ group as compared to VBAC group $(3.7 \%$ versus $1 \%) .3$ cases in which blood transfusion was required were from emergency LSCS group following failed TOL. One patient undergone subtotal hysterectomy for uncontrolled atonic PPH from repeat CS group.

Yap OWS et al, proposed that - Neonatal outcomes of elective caesarean delivery were at increased risk of developing respiratory problems. ${ }^{18}$ Fisler $\mathrm{RE}$ et $\mathrm{Al}$ reported no significant difference in 5-minute Apgar scores between infants in TOL groups versus infants in ERCD groups. ${ }^{19}$ The results also predict that complications following successful vaginal delivery were much less than emergency caesarean sections. In present study there were 5 cases of RDS of which $3(60 \%)$ cases were from VBAC group and 2(40\%) cases were from repeat $\mathrm{CS}$ group. In the present study Out of 8 cases of abnormal 5 minute Apgar score 5(62.5\%) were from vaginal deliveries and $3(37.5 \%)$ were from emergency LSCS after failed TOLAC. Above findings suggesting no significant difference in the two groups in respiratory problems and 5-minute Apgar scores.

After reviewing the health status and parity of these women, VBAC should be encouraged with strict fetomaternal monitoring during labour in hospitals. In underdeveloped countries, the non-availability of modern neonatology equipment leads to a higher rate of complication in neonates.

Nigam A. et al perinatal morbidity was seen in $6.4 \%$ of the patients who delivered by a repeat caesarean delivery. ${ }^{13}$ There were no NICU admissions for babies born to the patients who had a successful VBAC in this study. In that study the most common cause for morbidity, was Respiratory Distress Syndrome (RDS), followed by birth asphyxia. All of the 3 neonates were subsequently discharged healthy from the NICU.

In the present study, there were total 14 NICU admissions, which constituted $5.6 \%$ (14/249) of all births. Out of these 8 cases were from VBAC group and 6 were from repeat $\mathrm{CS}$ group. The most common indications for NICU transfer were respiratory distress syndrome, and not cried immediately after birth. One neonatal death noted in present study.

The strength of this study was that data were extracted from a database by trained health staff in a real clinical setting. In limitations of this study the possibility that bias affected the results of this study must be considered. Difference in characteristics in women who opted for TOL, women with spontaneous onset of labour and women who underwent ERCS might affect maternal and perinatal outcomes. Complications that occurred after discharge from the hospital may have been missed.

\section{CONCLUSION}

In the present study it is concluded that women with good Bishop score, spontaneously came in labour, interconceptional period more than 2 years and history of previous vaginal delivery had more rate of successful VBAC than women who had poor bishop score and who required induction. Women with VBAC, had the benefits of shorter hospital stay, decreased morbidity and less expenditure and comparable neonatal outcomes .Considering the fact that fetal morbidity and mortality due to TOL is comparable with the women labouring without a scar, It was found that success of TOLAC depend upon proper counseling for trial of scar and evaluation of prior caesarean section to reduce the caesarean section rate. Although a trial of labor is a relatively safe procedure, but it is not risk free .TOL may be encouraged. It is essential to counsel patients with a history of prior LSCS, ideally during the antenatal period, regarding the benefits and the risks (both maternal and perinatal) of a VBAC, and probably bring down the repeat caesarean rate. 
In women decided for TOL, careful observation throughout labor in a well-equipped unit with around the clock services for emergency surgery and availability of expertise is the backbone for successful trial of scar. Women can be given TOL with careful monitoring and taken for emergency LSCS on minimal indication and is the best answer to management of previous one CS in labour at our hospital.

\section{ACKNOWLEDGMENTS}

Authors would like to thank Dr Y Balasubbaiah for encouragement and inspiration throughout the study period. Author is very greatful to Dr Jyothi S for giving opportunity to conduct this study and always being helpful. Authors would like to thank Dr.Sumathi Balakuduru for guiding in the concept of the study. Author very greatful to Dr.Shalaka A Bansode for playing major role in the writing and interpreting the study results. Author thankful to the staff in labour room, for their immense help during the whole period of study. Finally, Author wish to thank to the patients and infants who participated in this study. Without their trust and cooperation, this study would not have been possible.

Funding: No funding sources

Conflict of interest: None declared

Ethical approval: Not required

\section{REFERENCES}

1. American College of Obstetricians and Gynecologists. ACOG Practice Bulletin No. 115: Vaginal birth after previous caesarean delivery. Obstet Gynecol. 2010;116(2Pt 1):450-63.

2. A. Vogel JP, Betrán AP, Vindevoghel N, Souza JP, Torloni MR, Zhang J. WHO multi-country survey on maternal and newborn Health Research network: use of the Robson classification to assess caesarean section trends in 21 countries: a secondary analysis of two WHO multicountry surveys. Lancet Glob Health. 2015;3(5):e260-70.

3. Cragin EB. Conservatism in Obstetrics. N Y Med J 1916;104:1-3.

4. Joseph GF, Stedman CM, Robichaux AG. Vaginal birth after cesarean section: the impact of patient resistance to a trial of labor. Am J Obstet Gynecol. 1991;164:1441-7.

5. Agarwal A, Gupta HP, Anand S, Das K. Vaginal birth after cesarean - A partographic analysis. J Obst Gyn India. 2002;52:85-9.

6. Landon MB, Leindecker S, Spong CY, Hauth JC, Bloom S, Varner MW, et al. The MFMU caesarean registry: Factorsaffecting the success of trial of labour after previous caesareandelivery. Am J Obstet Gynecol 2005;193:1016-237

7. Grobman WA, Gilbert S, Landon MB, Spong CY, Leveno KJ, Rouse DJ, et al. Outcomes of induction of labor after one prior cesarean. Obstet Gynecol 2007;109:262-9. (LevelI-2).

8. Sims EJ, Newman RB, Hulsey TC. Vaginal birth after cesarean: to induce or not to induce. Am J Obstet Gynecol. 2001;184:1122-4.

9. Shipp TD, Zelop CM, Repke JT. Interdelivery interval and risk of symptomatic uterine rupture. Obstet Gynecol. 2001;97:175.

10. Phelan JP, Clark SL, Diaz F, Paul RH. Vaginal birth after caesarean. Am J Obstet Gynecol. 1987; $157: 1510-5$.

11. Dayal V. Trial of vaginal delivery in cases of single previous cesarean section. J Obstet Gynecol. 1985;35:445-50.

12. The American college of Obstetricians and Gynecologists (ACOG) [27] ACOG practice bulletin. Vaginal birth after previous cesarean delivery. No. 2, October 1998. Clinical management guidelines for obstetrician-gynecologists. American College of Obstetricians and Gynecologists. Int J Gynaecol Obstet. 1999;64:201-8.

13. Nigam A. Research Article Study of obstetric and fetal outcome of post caesarean pregnancy. International J Reproduction, Contraception, Obstetr Gynecol. 2015;4(1):215-8.

14. Mozurkewich and Hutton. Estimates of maternal morbidity, however, have produced conflicting results. In the meta-analysis by Mozurkewich and Hutton 2000.

15. Traynor JD, Peaceman AM. Maternal hospital chargesassociated with trial of labour versus elective repeat caesareansection. Birth. 1998;25:81-4.

16. Horowitz BJ, Stanley W, Lippmann L. Once a cesarean, always a caesarean. Obstet Gynaec Survey. 1981;36:592-7.

17. Hibbard JU, Ismail MA, Wang Y, Te C, Karrison T, Ismail MA. Failed vaginal birth after cesarean section: how risky is it.Maternal morbidity? Am J Obstet Gynecol. 2001;184:1365-71.

18. Yap OWS, Kim ES, Laros RK. Maternal and neonatal outcomes after uterine rupture in labor. Am J Obstet Gynecol. 2001;184:1576-81.

19. Fisler RE, Cohen A, Ringer SA, Lieberman E. Neonatal outcome after trial of labor compared with elective repeat cesarean section. Birth. 2003;30(2):83-8.

Cite this article as: Ingle SP, Bansode $S$, Balakuduru S. Maternal and perinatal outcome in trial of labour after caesarean at tertiary care hospital: a prospective observational study. Int J Reprod Contracept Obstet Gynecol 2021;10:315-20. 